\title{
INFECCIÓN POR Bordetella pertussis Y Bordetella parapertussis EN CASOS CON SOSPECHA DE COQUELUCHE (2011-2015). MAR DEL PLATA, ARGENTINA
}

\begin{abstract}
Silvina Lavayén ${ }^{1, a}$, Claudia Zotta ${ }^{1, b}$, Marcela Cepeda ${ }^{2, c}$, Claudia Lara ${ }^{3, d}$, Analia Rearte ${ }^{2, e}$, Mabel Regueira ${ }^{3, d}$ RESUMEN

Objetivos. Caracterizar la población en estudio en el marco del Sistema Nacional de Vigilancia de Salud de la Argentina, determinar la proporción de infección por Bordetella pertussis y Bordetella parapertussis e identificar factores asociados de los casos con sospecha de coqueluche atendidos en la ciudad de Mar del Plata y alrededores durante el período 20112015. Materiales y Métodos. Se realizó un estudio observacional y descriptivo. Se diagnosticaron por laboratorio casos clínicos con sospecha de coqueluche. Los estudios de laboratorio consistieron en cultivo, PCR y serología por técnica de ELISA. Resultados. Se evaluaron 572 casos. El sexo femenino fue el más frecuente con $51,9 \%(296 / 570)$, el rango etario más frecuente fue de 2 a 17 meses con $51,1 \%$ (290/568) que fue además el grupo con más casos confirmados. Solo el $47,8 \%(155 / 324)$ de la población estudiada tenía vacunación completa para su edad. Se confirmó coqueluche por Bordetella pertussis en el 15,5 \% y un solo caso con Bordetella parapertussis. Hubo asociación entre tener un contacto familiar tosedor por más de dos semanas con la confirmación de Bordetella spp. (odds ratio [OR]: 3,3; [intervalo de confianza al 95\%] IC 95\%: $1,9-5,4)$. Conclusiones. Existe la necesidad de realizar una evaluación oportuna de los casos sospechosos de coqueluche tanto en niños como en adolescentes y adultos para lograr un mejor control de la enfermedad. Asimismo, continuar con las medidas de prevención y de contención resulta fundamental para disminuir la circulación del agente causal.
\end{abstract}

Palabras claves: Bordetella pertussis; Bordetella parapertussis; Coqueluche; Vigilancia (fuente: DeCS BIREME).

\section{INFECTION BY Bordetella pertussis AND Bordetella parapertussis IN CASES OF SUSPECTED WHOOPING COUGH (2011-2015) IN MAR DEL PLATA, ARGENTINA}

\begin{abstract}
Objectives. To classify the study population in the Argentinian National Health Surveillance System framework, determine the proportion of infection by Bordetella pertussis and Bordetella parapertussis, and identify factors associated with the cases of suspected whooping cough attended to in the city of Mar del Plata and its outskirts during the period 20112015. Materials and Methods. An observational and descriptive study was carried out. Clinical cases with suspicion of whooping cough were diagnosed by laboratory. The laboratory studies consisted of culture, PCR, and serology using the ELISA technique. Results. A total of 572 cases were evaluated. The female sex was the most frequent $(51.9 \%)$. The most frequent age range was 2 to 17 moths (51.1\%; 290/568), which was also the group with the most confirmed cases. Only $47.8 \%(155 / 324)$ of the population studied had complete vaccination for their age. Whooping cough due to B. pertussis was confirmed in $15.5 \%(89 / 572)$ of cases and one case with B. parapertussis. Those cases that had contact with a coughing relative were significantly associated with the confirmation of Bordetella spp. by the laboratory (odds ratio: 3.3 ; $95 \%$ confidence interval: 1.9-5.4). Conclusions. The results show the need to suspect whooping cough and diagnose it early in children, adolescents, and adults in order to better control the disease. Likewise, continuing prevention and containment measures are fundamental in decreasing the circulation of the causal agent.
\end{abstract}

Key words: Bordetella pertussis; Bordetella parapertussis, Whooping cough; Surveillance (source: MeSH NLM).

\section{INTRODUCCIÓN}

El coqueluche, pertussis o tos convulsa es una enfermedad aguda de la infancia que afecta a las vías respiratorias; es altamente contagiosa y es causada principalmente por la Bordetella pertussis (BP), cocobacilo gramnegativo, capsulado, inmóvil y aerobio facultativo. En menor grado otro agente causal es la Bordetella parapertussis (BPP). La sintomatología varía desde un cuadro leve hasta una forma severa. Esta enfermedad, declarada reemergente por la Organización Mundial de la Salud (OMS), afecta a todos los grupos

\footnotetext{
Instituto Nacional de Epidemiología "Dr. Juan H. Jara”. Buenos Aires, Argentina.

Hospital Interzonal Especializado Materno Infantil “Victorio Tetamanti”. Buenos Aires, Argentina.

Instituto Nacional de Enfermedades Infecciosas. Buenos Aires; Argentina.

Química; ${ }^{\mathrm{b}}$ técnico químico; ${ }^{\mathrm{c}}$ enfermera en Infectología y Epidemiología; ${ }^{\mathrm{d}}$ bioquímica; ${ }^{\mathrm{e}}$ médico pediatra.

Recibido: 14/07/2016 Aprobado: 22/02/2017 En línea: 23/03/2017
} 
de edad constituyéndose el grupo de mayor riesgo los menores de 6 meses (1) quienes suelen dar la alerta clínica por ser la población más vulnerable. En cambio en los adolescentes y adultos, si bien la enfermedad puede presentarse con paroxismos, suele presentarse de forma más leve con tos seca de larga duración ${ }^{(2)}$.

La OMS informó que mundialmente el número de casos de coqueluche estuvo cerca de los 170000 para el año 2011 y casi 250000 para el 2012. En América se estimaron unos 30000 casos para el 2011 y algo más de 70000 para 2012, quedando 2013 y 2014 con valores intermedios ${ }^{(3)}$. En Argentina las tasas de incidencia por 100000 habitantes fueron de 6,$9 ; 4,7 ; 2,7 ; 1,4 ;$ y 2,2 respectivamente para los años del 2011 al $2015^{(4)}$.

Si bien el coqueluche era ya una patología de notificación obligatoria, desde el 2003 el Ministerio de Salud de la Nación de Argentina (MSAL) creó el Sistema Nacional de Vigilancia de Salud (SNVS) e implementó el Módulo de Vigilancia por Laboratorio (SIVILA) de coqueluche a partir del Laboratorio Nacional de Referencia (LNR) ${ }^{(5)}$. Los objetivos del SIVILA incluyen descartar o confirmar los casos sospechosos, alertar tempranamente acerca de eventos que requieran medidas de control inmediato, colaborar en la identificación y caracterización de brotes y epidemias y proveer información acerca de la frecuencia y distribución de agentes productores de enfermedades y riesgos.

A partir del año 2011, el SNVS, basándose en la mejora en el diagnóstico, incorporó la variable "clasificación epidemiológica" que permitió definir a los casos de coqueluche como confirmados, probables y no conclusivos ${ }^{(5)}$. A partir de esa fecha, la notificación registrada por el SIVILA ha presentado un gran incremento ${ }^{(6)}$.

Según el SIVILA, para el año 2011 se registraron 1071 casos confirmados por laboratorio de coqueluche en Argentina; a partir del 2012 el número de casos disminuyó, tendencia que se prolongó durante los años 2013 y 2014. Durante el 2015 se produjeron 875 casos confirmados ${ }^{(4)}$.

Varias son las causas que se han propuesto para explicar el resurgimiento de esta enfermedad, tales como la distribución no homogénea de la vacunación ${ }^{(7)}$, la corta duración de la inmunidad conferida por las vacunas, la aparición de cuadros clínicos atípicos y aparición de cepas de BP circulantes con variantes antigénicas respecto a las cepas incluidas en las vacunas ${ }^{(8)}$. Esto conlleva a la aparición de otro perfil epidemiológico pues además de afectar a la población lactante esta enfermedad se presenta también en población adolescente y adulta ${ }^{(9)}$, quienes se transforman en la principal fuente de contagio ${ }^{(10)}$.
La OMS estima que la tasa de letalidad en países en desarrollo puede llegar hasta un 4\% (7,10). En Argentina, particularmente durante el año 2011, fallecieron 76 personas, cantidad que fue superior a la alcanzada en años previos, y que además estuvo concentrada en los lactantes menores de 1 año ${ }^{(6,11)}$. Para el 2015 se registró el fallecimiento de diez niños del mismo grupo de edad ${ }^{(4)}$.

La vigilancia intensificada de la enfermedad permite monitorear el comportamiento de la enfermedad y mejorar la toma de decisiones adecuadas y oportunas en la población. Los objetivos del presente trabajo fueron caracterizar la población en estudio en el marco del SNVS de la Argentina, determinar la proporción de infección por BP y BPP e identificar factores asociados de los casos de coqueluche atendidos en la ciudad de Mar del Plata y alrededores durante el período 2011-2015.

\section{MATERIALES Y MÉTODOS}

Se realizó un estudio observacional y descriptivo. Se analizó la información clínico-epidemiológica-laboratorial de 574 casos con sospecha de coqueluche durante el período comprendido entre enero de 2011 y diciembre de 2015 recibidas en el Servicio de Bacteriología del Instituto Nacional de Epidemiología (INE). Las fichas y las muestras de aspirado nasofaríngeo (ANF) o esputos y sueros provenían de servicios de salud privados, centros de atención primaria, hospitales municipales de Mar del Plata y alrededores y del Hospital Interzonal Especializado Materno Infantil "Victorio Tetamanti" (HIEMI). El HIEMI es uno de los seis hospitales provinciales de la región Sanitaria VIII de la provincia de Buenos Aires que comprende 15 partidos, donde residen algo más de 1 millón de habitantes.

\section{CRITERIOS DE SELECCIÓN}

Fueron incluidos todos aquellos pacientes que cumplieran con la definición de caso de coqueluche que tuvieran la ficha clínica epidemiológica; se excluyeron aquellos cuyas muestras no fueran aptas para el diagnóstico o que no tuvieran ficha epidemiológica, respetando el algoritmo de trabajo del LNR ${ }^{(12)}$.

\section{MUESTRAS}

Se realizó cultivo y reacción en cadena de la polimerasa (PCR) a todos los casos pediátricos en muestra de ANF y también a adolescentes o adultos de quienes se remitió ANF o esputo. La serología se utilizó solo para adolescentes y adultos. Los casos se notificaron al SIVILA según la clasificación consensuada con el MSAL.

\section{DEFINICIÓN DE CASO}

Se utilizaron las definiciones de caso acordadas entre el MSAL y el LNR ${ }^{(5)}$ : menores de 6 meses, toda infección 
respiratoria aguda con al menos uno de los siguientes síntomas: apnea, cianosis, estridor inspiratorio, vómitos después de toser o tos paroxística; mayores de 6 meses hasta 11 años, tos de catorce o más días de duración acompañado de uno o más de los siguientes síntomas: tos paroxística, estridor inspiratorio o vómitos después de la tos, sin otra causa aparente, mayores de 11 años, tos persistente de catorce o más días de duración sin otra sintomatología acompañante.

\section{VARIABLES EN ESTUDIO}

Las variables estudiadas fueron sexo (femenino/ masculino), edad (menores de 2 meses, de 2 a 17 meses, de 18 meses a 6 años y mayores o igual a 7 años), tiempo de evolución de síntomas al momento de toma de muestra (número de días de evolución informados por el médico tratante), estacionalidad tomada como las cuatro estaciones de año (otoño, invierno, primavera y verano), condición del paciente (ambulatorio o internado), existencia de contacto familiar con síntomas como tos persistente sin causa aparente (sí/no), estado de vacunación (completa para la edad, cuando cumplía el calendario nacional de vacunación; incompleta, cuando faltaba al menos una dosis para la edad; y no correspondía, en el caso de los niños menores de 2 meses), evolución final (favorable o muerte) y resultado de laboratorio.

Las diferentes categorías de la edad se tomaron considerando el plan de vacunación vigente en Argentina. El estado de vacunación fue consignado por ficha epidemiológica de acuerdo a lo reportado por el paciente o la madre si era un menor.

Para el informe del resultado de laboratorio y la notificación en SIVILA se utilizaron los siguientes criterios establecidos por el MSAL ${ }^{(5,12)}$ : caso confirmado de coqueluche por $B P$, clínica compatible y alguno de los siguientes resultados: cultivo positivo para BP o PCR positiva o resultado positivo de serología; caso confirmado de coqueluche por Bordetella spp., clínica compatible y alguno de los siguientes resultados: serología pareada con variación de dos títulos o más entre la primera segunda muestra de suero (este criterio fue cambiado a partir del 2015 por resultado positivo de serología); caso confirmado de coqueluche por BPP, clínica compatible y alguno de los siguientes resultados: cultivo positivo para BPP o PCR positiva para BPP; caso no conclusivo, casos estudiados por laboratorio con resultados negativos.

\section{DIAGNÓSTICO DE LABORATORIO}

El diagnóstico se realizó en muestras de ANF, muestras de esputo y/o suero de pacientes internados $y$ ambulatorios con sintomatología clínica compatible con coqueluche.

\section{CULTIVO}

El cultivo se considera aún el método de referencia en el diagnóstico de laboratorio de coqueluche. La especificidad es del 100\%; puede ser negativo en pacientes inmunizados, en los que han comenzado tratamiento antibiótico o en los que llevan más de tres semanas de evolución de la tos. El cultivo de ANF y de esputo se realizó mediante la siembra en medio Bordet Gengou Agar base (Difco, Ref: 248200) suplementado con $10 \%$ sangre ovina desfibrinada estéril (Britasheep, Britania; Código B0360860) ${ }^{(13,14)}$ sin agregado de cefalexina. Las placas se incubaron hasta diez días antes de clasificarlas como negativas, a $36^{\circ} \mathrm{C}$ y en atmósfera de humedad.

\section{REACCIÓN EN CADENA DE LA POLIMERASA}

Las muestras de ANF y esputo fueron tratadas con proteinasa $\mathrm{K}(20 \mathrm{mg} / \mathrm{mL})$, incubados a $56^{\circ} \mathrm{C}$ durante 60 min. Se centrifugaron a 7000 revoluciones por minuto (rpm) durante 5 min luego de hervir en baño de agua a $100{ }^{\circ} \mathrm{C}$ durante $15 \mathrm{~min}$. El extracto de ADN se conservó a $4{ }^{\circ} \mathrm{C}$ para ser utilizado como templado. Para realizar la PCR múltiple se utilizaron los pares de oligonucleótidos iniciadores para determinar la secuencia de inserción IS481 para la detección de BP y la secuencia de inserción IS1001 para la detección de BPP.

Para la confirmación se utilizó otra PCR que detectaba la secuencia promotora de la toxina pertussis (ptx), específica para BP ${ }^{(15)}$. Se utilizaron controles internos y controles negativos para asegurar la ausencia de inhibición y contaminación, respectivamente.

\section{PREPARACIÓN DE MEZCLA DE REACCIÓN}

Se utilizaron $20 \mu \mathrm{L}$ finales de mezcla de reacción de PCR múltiple, conteniendo $2 \mu \mathrm{L}$ de buffer para PCR 10X (Invitrogen Life Technologies, Brasil), 1,2 $\mu \mathrm{L}$ de mezcla de dNTPs $2 \mathrm{mM}$ (Promega), 1,2 $\mathrm{LL}$ de $\mathrm{MgCl}_{2}$ $50 \mathrm{Mm}$ (Invitrogen), $1 \mu \mathrm{L}$ del par de cebadores para IS481 (Invitrogen), $1 \mu \mathrm{L}$ del par de cebadores para IS1001(Invitrogen), 0,2 $\mu \mathrm{L}$ de taq ADN polimerasa $5 \mathrm{U} / \mathrm{mL}$ (Invitrogen), 10,4 $\mu \mathrm{L}$ de agua tridestilada estéril y $3 \mu \mathrm{L}$ de ADN templado.

Para la PCR de confirmación por ptx la mezcla contenía: $2 \mu \mathrm{L}$ de buffer para PCR 10X (Invitrogen Life Technologies, Brasil), 1,2 $\mu \mathrm{L}$ de mezcla de dNTPs $2 \mathrm{mM}$ (Promega), 1,2 $\mu \mathrm{L}$ de $\mathrm{MgCl}_{2} 50 \mathrm{Mm}$ (Invitrogen), $2 \mu \mathrm{L}$ del par de cebadores para ptx (Invitrogen), 0,2 $\mu \mathrm{L}$ de taq ADN polimerasa $5 \mathrm{U} / \mathrm{mL}$ (Invitrogen), 10,4 $\mu \mathrm{L}$ de agua tridestilada estéril y $3 \mu \mathrm{L}$ de ADN templado.

Se utilizó un termociclador Multigene TC9600 (Labnet, Edison, NJ, EE.UU.). Las condiciones de amplificación 
fueron a $94{ }^{\circ} \mathrm{C}$ por $1 \min 15 \mathrm{~s}$, seguidos de 35 ciclos a $94{ }^{\circ} \mathrm{C}$ por $15 \mathrm{~s}$, a $62{ }^{\circ} \mathrm{C}$ por $10 \mathrm{~s}$ y a $72{ }^{\circ} \mathrm{C}$ por $20 \mathrm{~s}$. La extensión final fue a $72{ }^{\circ} \mathrm{C}$ por $30 \mathrm{~s}$.

Se agregaron $2 \mu \mathrm{L}$ de una solución de xileno cianol al $0,25 \%$ y glicerol en agua al $30 \%$ (Sigma, St Louis, EE.UU.) a $20 \mu \mathrm{L}$ del ADN amplificado, sembrándose $10 \mu \mathrm{L}$ en un gel de agarosa (Invitrogen) al $2 \%$ en buffer para TAE $1 X$ (Invitrogen) y el marcador de peso molecular $100 \mathrm{bp}$ Molecular Rule (BioRad, Hercules, CA, EE.UU.).

\section{CORRIDA ELECTROFORÉTICA}

Las siembras se realizaron en $50 \mathrm{~mL}$ de gel de agarosa adicionado con $5 \mu \mathrm{L}$ de revelador (Syber Safe, Invitrogen, Ref: 1245418). Como buffer de corrida se usó TAE 10X (Invitrogen ref: 15558-042). Se realizó la corrida electroforética a $110 \mathrm{~V} / \mathrm{cm}$ (Labnet) durante $20 \mathrm{~min}$, Para revelar las bandas se utilizó un transiluminador de luz azul (Safe Imagen 2.0-Invitrogen).

\section{DIAGNOSTICO SEROLOGICO}

Para el diagnóstico serológico se derivaron las muestras de sueros de adolescentes y adultos al LNR. Entre 2011 y 2014 las muestras de suero fueron estudiadas mediante ELISA para detección de anticuerpos totales anti Bordetella spp. Se requerían dos muestras de suero tomadas con un intervalo de veintiún días de diferencia. Se consideró resultado positivo si entre la primera y la segunda muestra de suero existía una diferencia de dos o más títulos. A partir del año 2015 se implementó la detección anticuerpos lgG anti ptx mediante la técnica de ELISA en una única muestra de suero. Se utilizó el protocolo desarrollado por CDC. El ensayo fue calibrado contra el patrón internacional "Standard 06/140" de la OMS. Se consideró positivo un resultado mayor a 93 $\mathrm{UI} / \mathrm{mL}$.

\section{ANÁLISIS ESTADÍSTICO}

Con el objetivo de caracterizar la muestra estudiada, se realizó un análisis univariado en cada variable de modo independiente; se trabajó con distribuciones de frecuencias, medidas de tendencia central y medidas de dispersión con un nivel de significancia del $5 \%$.

Para las variables dicotómicas se realizó el análisis a través de tablas de contingencia considerando el porcentual de diagnósticos positivos en cada subgrupo; el odds ratio (OR) y su respectivo intervalo de confianza al 95\% (IC95\%). El análisis descriptivo de variables en estudio y el cálculo de medidas de tendencia central se realizó mediante el uso del paquete Epidat versión 3.1. Para el cálculo de comparación de proporciones se utilizó el Epidat 4.1.

\section{CONSIDERACIONES ÉTICAS}

El presente trabajo se limitó al estudio retrospectivo de datos provenientes de la atención médica producto de la vigilancia epidemiológica de esta patología. Los datos se mantuvieron encriptados de manera tal que se garantizó la privacidad y confidencialidad de los mismos de acuerdo a la Ley 25326 de Protección de datos Personales. El trabajo fue revisado por el Comité de Ética en Investigación del INE, considerándose científicamente aceptable, según lo establece la Declaración de Helsinki de 1964 y sucesivas enmiendas, Resolución 1480/2011 de la Guía para Investigaciones con Seres Humanos y la Ley 11044 de Investigación en salud - Aspectos éticos de la investigación en seres humanos.

\section{RESULTADOS}

Luego de la exclusión de un número de muestras por no cumplir con criterios técnicos o de selección, se procesaron en total 521 muestras de ANF, 19 serológicas y 46 de esputo, que en conjunto correspondieron a 572 pacientes. Algunos de estos tuvieron más de una muestra (Figura 1). Solo se realizó la prueba ELISA para detección de anticuerpos totales anti Bordetella spp. La técnica de ELISA para detección de lgG anti TP se puso en práctica a partir del 2015 y no se obtuvo ninguna muestra de suero en ese año.

La distribución por edad mostró un rango entre 1 mes y 62 años y una mediana de 2 meses (rango intercuartílico: 4 meses). Dentro de los grupos etarios, el rango comprendido entre los 2 y 17 meses fue el más frecuente $(51,1 \% ; 290 / 568)$, seguido de los menores de 2 meses (34,5\%; 196/568), más de 7 años $(9,7 \%$; $55 / 568)$ y entre los 18 meses y los 6 años $(4,7 \%$; $27 / 568)$. El sexo femenino fue el más frecuente con 51,9\% (296/570); el lugar de procedencia correspondió principalmente a tres localidades: Mar del Plata $(74,7 \%)$, Necochea $(14,1 \%)$ y Balcarce $(6,5 \%)$.

La mayor frecuencia de casos confirmados respecto a la edad correspondió al intervalo comprendido entre los 2 y 17 meses $(45,4 \%)$ seguido de los menores de 2 meses $(40,9 \%)$, el estado de atención hospitalaria más frecuente fue el estar internado al momento del estudio (88,9\%); en ambos casos las proporciones no fueron estadísticamente diferentes. Además, se encontró que tanto las estaciones primavera e invierno eran las que presentaban más casos (50,0 y 25,5\%, respectivamente). Tanto en lo grupos confirmados como no concluyentes la evolución fue favorable en la mayoría de los casos (Tabla 1). 


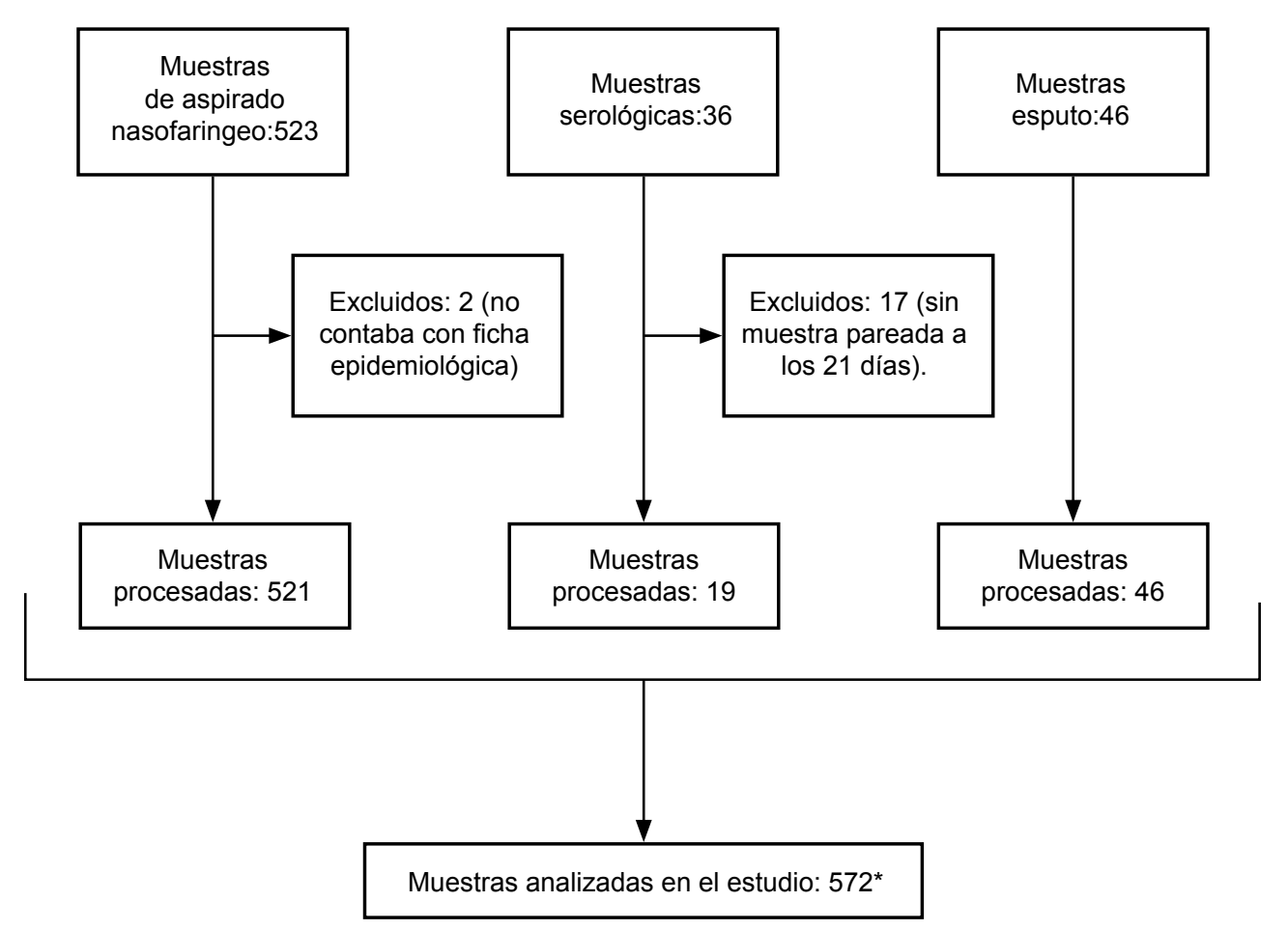

* Muestras de 553 pacientes solo para PCR, de catorce pacientes para PCR y serología, y de cinco pacientes solo para serología.

Figura 1. Flujograma del estudio

De los 572 casos estudiados se confirmó coqueluche debido a BP y Bordetella spp. en el 15,5\%. Se encontró solo un caso con resultado positivo para BPP (Tabla 2).

Solo fue posible conocer el estado de vacunación en 520 pacientes. En todos los menores de 2 meses (196) no correspondía la vacunación; en los siguientes grupos etarios solo se presentaban dos estados (vacunación completa o incompleta), la frecuencia de vacunación completa en el grupo de 2 a 17 meses fue de $51,5 \%$ (134/276), de 65,0\% (13/20) en el grupo de 18 meses a 6 años y de $25,9 \%$ (7/27) en el grupo mayor de 7 años. Se confirmó coqueluche en el 12,9\% (20/155) de los casos estudiados que confirmaron un esquema completo de vacunación de acuerdo a la edad al momento de la toma de muestra.

Cuando se compararon los diferentes estados de vacunación y su asociación con tener el diagnóstico confirmado de coqueluche, la prueba de homogeneidad señaló que no diferían entre los grupos comparados con el de referencia (estado de vacunación: completa) $(p=0,365)$.

Se obtuvo cultivo positivo en 17 casos (16 BP y 1 BPP). La proporción de positividad fue del 18,9\% (17/90). La media del tiempo de evolución de síntomas al momento de la toma de muestra de los casos con cultivo positivo fue $6,3 \pm 4,2$ días y un rango de 1 a 15 días.

El 26,3\% (5/19) de los casos estudiados por serología mostraron seroconversión con una media de tiempo de evolución de síntomas al momento de la toma de muestra de 27,0 $\pm 19,4$ días y un rango entre siete y 55 días.

En el 2011 se obtuvo una proporción de $22,6 \%$ de casos positivos (64/283), en $2012,15,5 \%$ (20/129) y en 2015 , $10,7 \%(6 / 56)$. No se observaron diferencia significativa en la comparación de proporciones entre los años 2011-2012, ni 2012-2015; solo se observó diferencia significativa entre los años 2011-2015 $(p<0,05)$. Durante los años 2013 y 2014 no se registraron resultados positivos por laboratorio.

Se observó un aumento del 10 al $33,3 \%(p>0,05)$ entre el 2011 y 2015 para coqueluche confirmado en chicos de 18 meses de edad a 6 años, y para los mismos años un aumento del 5 al $16,7 \%(p>0,05)$ en los de 7 años o más.

En el año 2011 se consignaron ocho defunciones de los 64 casos confirmados, calculándose una tasa de letalidad de $12,5 \%$. Se registró un óbito de los seis casos 
Tabla 1. Características generales de la población

\begin{tabular}{|c|c|c|c|}
\hline \multirow{3}{*}{ Característica } & \multicolumn{2}{|c|}{ Coqueluche } & \multirow{3}{*}{$\begin{array}{l}\text { Valor } \\
\text { de } p\end{array}$} \\
\hline & Confirmado & $\begin{array}{c}\text { No } \\
\text { concluyente }\end{array}$ & \\
\hline & n (\%) & n (\%) & \\
\hline \multicolumn{3}{|l|}{ Sexo $(n=570)$} & $0,150^{*}$ \\
\hline Femenino & $53(58,9)$ & $243(50,6)$ & \\
\hline Masculino & $37(41,1)$ & $237(49,4)$ & \\
\hline \multicolumn{3}{|c|}{ Estado de vacunación $(n=520)$} & $0,365 \dagger$ \\
\hline Completa & $20(24,4)$ & $135(30,8)$ & \\
\hline Incompleta & $26(31,7)$ & $143(32,7)$ & \\
\hline No corresponde & $36(43,9)$ & $160(36,5)$ & \\
\hline \multicolumn{3}{|l|}{ Edad $(n=568)$} & $0,12 \dagger$ \\
\hline$<2$ meses & $36(40,9)$ & $160(33,3)$ & \\
\hline $2-17$ meses & $40(45,4)$ & $250(52,1)$ & \\
\hline $\begin{array}{l}18 \text { meses - } 6 \\
\text { años }\end{array}$ & $7(8,0)$ & $20(4,2)$ & \\
\hline$\geq 7$ años & $5(5,7)$ & $50(10,4)$ & \\
\hline \multicolumn{3}{|c|}{ Atención hospitalaria $(n=572)$} & $0,069^{*}$ \\
\hline Internado & $80(88,9)$ & $390(80,9)$ & \\
\hline Ambulatorio & $10(11,1)$ & $92(19,1)$ & \\
\hline \multicolumn{3}{|c|}{ Estacionalidad $(\mathrm{n}=572)$} & $<0,001$ \\
\hline Otoño & $6(6,7)$ & $156(32,4)$ & \\
\hline Primavera & $45(50,0)$ & $195(40,5)$ & \\
\hline Invierno & $23(25,5)$ & $86(17,8)$ & \\
\hline Verano & $16(17,8)$ & $45(9,3)$ & \\
\hline \multicolumn{3}{|c|}{ Contacto familiar $(n=488)$} & $<0,001^{*}$ \\
\hline Sí & $52(64,2)$ & $144(35,4)$ & \\
\hline No & $29(35,8)$ & $263(64,4)$ & \\
\hline \multicolumn{3}{|l|}{ Evolución (n=572) } & $p<0,001 \ddagger$ \\
\hline Favorable & $81(90,0)$ & $479(99,4)$ & \\
\hline Muerte & $9(10,0)$ & $3(0,6)$ & \\
\hline
\end{tabular}

${ }^{*}$ chi cuadrado. $†$ prueba de homogeneidad entre niveles. łcomparación de proporciones.

confirmados en el 2015 , con una letalidad de $16,6 \%$, y sin registro de defunciones para los años 2012, 2013 y 2014.

Del total de casos estudiados se obtuvo dato de presencia/ausencia de contactos en 488 casos. El $40,0 \%$ de ellos (196/488) tuvo al menos un contacto familiar con tos persistente al momento de la toma de muestra. Se observó una proporción significativamente menor de coqueluche confirmado en aquellos pacientes con una evolución favorable $(14,5 \% ; 81 / 560)$ respecto de aquellos que fallecieron $(75,0 \% ; 9 / 12)$.

Se encontró asociación significativa entre los casos confirmados y la condición de poseer un contacto con tos al momento de la toma de muestra (OR: 3,3; IC95\%: $1,9-5,4)$. De igual forma, también se pudo establecer que la condición de no tener vacuna o tener esquema incompleto de vacunación constituyó un factor que aumentaba la probabilidad para el internamiento (OR: 1,9; IC95\%: 1,1 - 3,1).
Tabla 2. Distribución del diagnóstico de laboratorio de los casos estudiados

\begin{tabular}{|c|c|c|}
\hline Diagnóstico de laboratorio & $\mathbf{n}$ & $\%$ \\
\hline \multicolumn{3}{|l|}{ Coqueluche por Bordetella pertussis } \\
\hline $\begin{array}{l}\text { Prueba PCR IS481 positiva + PCR ptx } \\
\text { positiva + cultivo positivo }\end{array}$ & 16 & 2,8 \\
\hline $\begin{array}{l}\text { Prueba PCR IS481 positiva + PCR ptx } \\
\text { positiva }\end{array}$ & 67 & 11,7 \\
\hline $\begin{array}{l}\text { Prueba PCR IS481 positiva + PCR ptx } \\
\text { positiva + seroconversión }\end{array}$ & 2 & 0,3 \\
\hline \multicolumn{3}{|l|}{ Coqueluche por Bordetella spp. } \\
\hline Prueba PCR IS481 positiva & 1 & 0,2 \\
\hline Seroconversión & 3 & 0,5 \\
\hline \multicolumn{3}{|l|}{ Coqueluche por Bordetella parapertussis } \\
\hline Prueba PCR IS1001 positiva + cultivo positivo & 1 & 0,2 \\
\hline No conclusivo & 482 & 84,3 \\
\hline
\end{tabular}

PCR: reacción en cadena de la polimerasa; IS481: secuencia de inserción para detectar Bordetella pertussis; IS1001: secuencia de inserción para detectar Bordetella parapertussis; ptx: secuencia promotora de la toxina pertussis.

\section{DISCUSIÓN}

La utilización de las distintas metodologías permitió ampliar el periodo en el cual la enfermedad fue detectada en comparación con el tiempo de detección de cualquiera de las pruebas utilizadas en forma aislada. Se encontraron en el total de casos, tiempos de evolución de síntomas de un día hasta 55 días. Se sabe existen factores como la edad del paciente, la fase de la enfermedad, el estado inmunológico del paciente que influyen en la utilidad de las distintas pruebas utilizadas en el diagnóstico y que tales resultados deben ser analizados teniendo en cuenta los signos y síntomas de los casos ${ }^{(16)}$

El incremento de la confirmación de coqueluche en población joven y adulta podría ser consecuencia de un aumento en la notificación así como también de la mejora de la sospecha clínica, a partir de la difusión del hecho de que pueden ser potenciales fuentes de transmisión a lactantes (11); por lo tanto, es importante no solo la atención del menor que diera la alerta clínica sino también de la familia y los contactos que pudieran estar infectados ${ }^{(17,18)}$. Resulta de suma importancia profundizar aun más la búsqueda intencionada de la enfermedad en este grupo etario.

El coqueluche es una enfermedad inmunoprevenible. El Calendario Nacional Argentino de vacunación prevé un el plan de tres primeras dosis, a los 2, 4, y 6 primeros meses de edad; el primer refuerzo a los 18 meses y el segundo refuerzo a los 6 años. También contempla la vacuna triple bacteriana acelular para chicos de 11 años de edad y las embarazadas a partir de la semana veinte de gestación, los supervivientes de prematuros 
con peso menor de $1500 \mathrm{~g}$ y el personal de salud en contacto con niños ${ }^{(19)}$.

Sin considerar a aquellos que no les correspondía la vacunación, solo un 47,8\% (155/324) de la población en estudio tenía la vacunación completa, a diferencia del $57 \%$ encontrado en un estudio realizado en Barcelona ${ }^{(20)}$ por lo que se requeriría el establecimiento de campañas de vacunación y mejoramiento del monitoreo en el primer nivel de atención para que se dé cumplimiento del calendario de vacunación y así se pueda disminuir la morbimortalidad de la enfermedad ${ }^{(20,21)}$.

En este estudio no se pudo registrar la vacunación de las madres durante el embarazo; se sugiere que en próximos estudios se pueda evaluar tal situación y observar si los signos y síntomas son menos complicados, si se minimizan los días de internamiento o incluso se evita el mismo, debido a la transferencia de anticuerpos maternos ${ }^{(22)}$.

Puede verse en este estudio que tener el esquema completo de vacunación, disminuye el la probabilidad de internamiento, e implica en una pronta recuperación del paciente y el bienestar familiar.

El registro, análisis y difusión de los casos estudiados por los laboratorios junto con los datos clínicos y epidemiológicos de coqueluche permiten el conocimiento de una enfermedad inmunoprevenible que está hoy en la lista de patologías reemergentes, y contribuye a la toma de decisiones adecuadas y oportunas en la población.

Fuentes de financiamiento: el trabajo fue financiado por las diferentes instituciones intervinientes con el presupuesto asignado anualmente para trabajo de rutina, sin financiamiento extra.

Conflictos de interés: los autores declaran no tener conflictos de interés.

Contribución de autoría: SL realizó la concepción y diseño del estudio. CZ y MC realizaron la toma de muestras. SL, CZ, $M C$ y $C L$ realizaron el trabajo técnico laboratorial. CZ y $M C$ recolectaron los datos. SL desarrolló la base de datos, analizó e interpretó los datos. SL redactó el manuscrito. CL asistió en la redacción. CZ, AR, MR revisaron críticamente el manuscrito. Todos los autores aprobaron la versión final del manuscrito.

\section{REFERENCIAS BIBLIOGRÁFICAS}

1. Riva-Posse CA, Miceli IN. Evolución de la Coqueluche en la Argentina a finales del Siglo XX, Medicina (B Aires). 2005;65(1): 7-16.

2. Cofré J. Coqueluche en adultos y adolescentes. Rev Chil Infect. 2003; 20 (Supl 1): S52-8. doi: 10.4067/S071610182003020100009

3. Organización Mundial de la Salud. Global Health Observatory data repository, Pertussis reported cases by WHO region [Internet]. Ginebra: OMS; 2016 [citado 10 feb 2017]. Disponible en: http://apps.who.int/ gho/data/view.main.1520_43

4. Ministerio de Salud de la Nación de la República Argentina. Boletin Integrado de vigilancia $\mathrm{N}^{\circ} 321$ - semana epidemiológica 31 2016 [Internet]. Buenos Aires: MSAL; 2016 [citado 10 feb 2017]. Disponible en: http://campus. fsg.org.ar/pluginfile.php/4299/ mod_resource/content/0/COQUE_ BOLETIN_INTEGRADO_DE_ VIGILANCIA_-_MSAL.pdf

5. Sistema Nacional de Vigilancia de la Salud. Tutoriales para la notificación en el Sistema nacional de Vigilancia de Salud. (SNVS) y otros documentos de interés [Internet]. Buenos Aires: MSAL - OPS; 2010 [citado 26 abril 2016].
Disponible en: http://publicaciones. ops.org.ar/publicaciones/ publicaciones\%20virtuales/SNVS/ SIVILA/tutorialCoqueluche.html.

6. Romanin V, Agustinho V, Califano G, Sagradini S, Aquino A, Juárez Mdel $\mathrm{V}$, et al. Situación epidemiológica de coqueluche y estrategias para su control: Argentina, 2002-2011. Arch Argent Pediatr. 2014;112(5):413-20. 10.5546/aap.2014.413

7. Tan T, Trindade E, Skowronski D. Epidemiology of Pertussis. Pediat Infect Dis J. 2005;24(5 Suppl):S10-8.

8. Xu Y, Liu B, Gröndahl-Yli-Hannuksila $\mathrm{K}$, Tan Y, Feng L, Kallonen T, et al. Whole-genome sequencing reveals the effect of vaccination on the evolution of Bordetella pertussis. Sci Rep. 2015;5:12888. doi: 10.1038/ srep12888

9. Moraga-Llopa FA, Campins-Martí M. Vacuna de la tos ferina. Reemergencia de la enfermedad y nuevas estrategias de vacunación. Enferm Infecc Microbiol Clin. 2015;33(3):190-6. doi: 10.1016/j.eimc.2015.02.001

10. Organización Panamericana de la Salud. Alerta Epidemiológica, Tos Ferina (Coqueluche) [Internet]. Washington D.C.: OPS; 2012 [citado
30 de nov 2016]. Disponible en: http://www.paho.org/hq/index. php?option $=$ com_docman\&task $=$ doc view\&gid=19325\&Itemid=270\&lang=es

11. Programa Nacional de Control de Enfermedades Inmunoprevenibles. Tos convulsa: Aumento de casos y muertes (semana epidemiológica 4) [Internet]. Buenos Aires: MSAL; 2012 [citado 10 feb 2017]. Disponible en: http:// www.msal.gob.ar/images/stories/bes/ graficos/0000000454cnt-2013-10 alerta-n01-tos-convulsa-2012.pdf

12. Ministerio de salud de la Nación de la República Argentina. COQUELUCHE - Algoritmo de diagnóstico por laboratorio y notificación a través del SIVILA [Internet]. Buenos Aires: MSAL; 2010 [citado 02 mar 2016]. Disponible en: http://www.msal.gov.ar/images/ stories/epidemiologia/vigilancia/ sivila/tutoriales/coqueluchealgoritmo-diagnostico-notificacionsivila-2010.pdf

13. Faulkner A, SkoffT, Martin S, Cassiday P, Tondella M, Liang J. Manual for the Surveillance of Vaccine-Preventable Diseases, Chapter 10: Pertussis [Internet]. Atlanta: CDC; 2011 [citado 10 feb 2017]. Disponible en: 
https://www.cdc.gov/vaccines/pubs/ surv-manual/chpt10-pertussis.html

14. Hozbor D, et al. Protocolo de trabajo de PCR para Bordetella pertussis. La Plata: Instituto de Bioquímica y Biología Molecular de la Universidad Nacional de La Plata; 2010.

15. Ministerio de Salud de la Nación de la República Argentina. Normativa y tutorial para La vigilancia a través del Sistema Nacional de Vigilancia Laboratorial SIVILA-SNVS Actualización 2011. Buenos Aires: MSAL; 2011.

16. Pérez-Pérez GF, Rojas-Mendoza T, Cabrera-Gaytán DA, Grajales-Muñiz C. Panorama epidemiológico de la tos ferina 19 años de estudio epidemiológico en el Instituto Mexicano del Seguro Social. Rev Med Inst Mex Seguro Soc. 2015;53(2):164-70.
17. Romero Quechol G, Tomé-Sandoval P, Torres-Arreola L, Guiscafré-Gallardo $\mathrm{H}$, Leaños-Miranda B. Identificación de un caso de tos ferina y estudio de sus contactos. Utilidad de la PCR y del cultivo. Rev Med Inst Mex Seguro Soc. 2007;45(6):623-7.

18. Lavayén, S, Zotta, C, Cepeda, M, Lara, C, \& Regueira, M. Ocurrencia de casos de Coqueluche en el seno familiar. Mar Del Plata, 2011. J Selva Andina Res Soc. 2013; 4(2):49-56.

19. Ministerio de Salud de la Nación de la República Argentina. Calendario Nacional de Vacunación [Internet]. Buenos Aires: MSAL; 2014 [citado 15 feb 2016]. Disponible en: http:// www.msal.gov.ar/index.php/home/ aranceles/184-calendario-nacional-devacunacion-2014.

20. Moraga-Llop FA, Mendoza-Palomar N, Muntaner-Alonso A, Codina-Grau
G, Fàbregas-Martori A, CampinsMartí M. Tos ferina en lactantes y niños bien vacunados. ¿Son necesarias nuevas estrategias de vacunación? Enferm Infecc Microbiol Clin. 2014;32(4):236-41. doi: 10.1016/j. eimc.2013.04.007

21. Gentile, A. Infección por Bordetella pertussis. Arch Argent Pediatr. 2010;108(1):78-81.

22. Fallo A, Manonelles G, Hozbor D, Lara C, Huespe M, Mazzeo S, et al. Estudio de seroprevalencia de coqueluche en adultos jóvenes, mujeres en puerperio inmediato y sangre del cordón umbilical. Arch Argent pediatr. 2014;112(4):315-22. doi: 10.5546/ aap. 2014.315

Correspondencia:Lic. Silvina Lavayén Dirección: Calle Ituzaingó 3520, Mar del Plata, Argentina.

Teléfono: (+54) 223-4732100

Correo electrónico: vayensil@hotmail.com

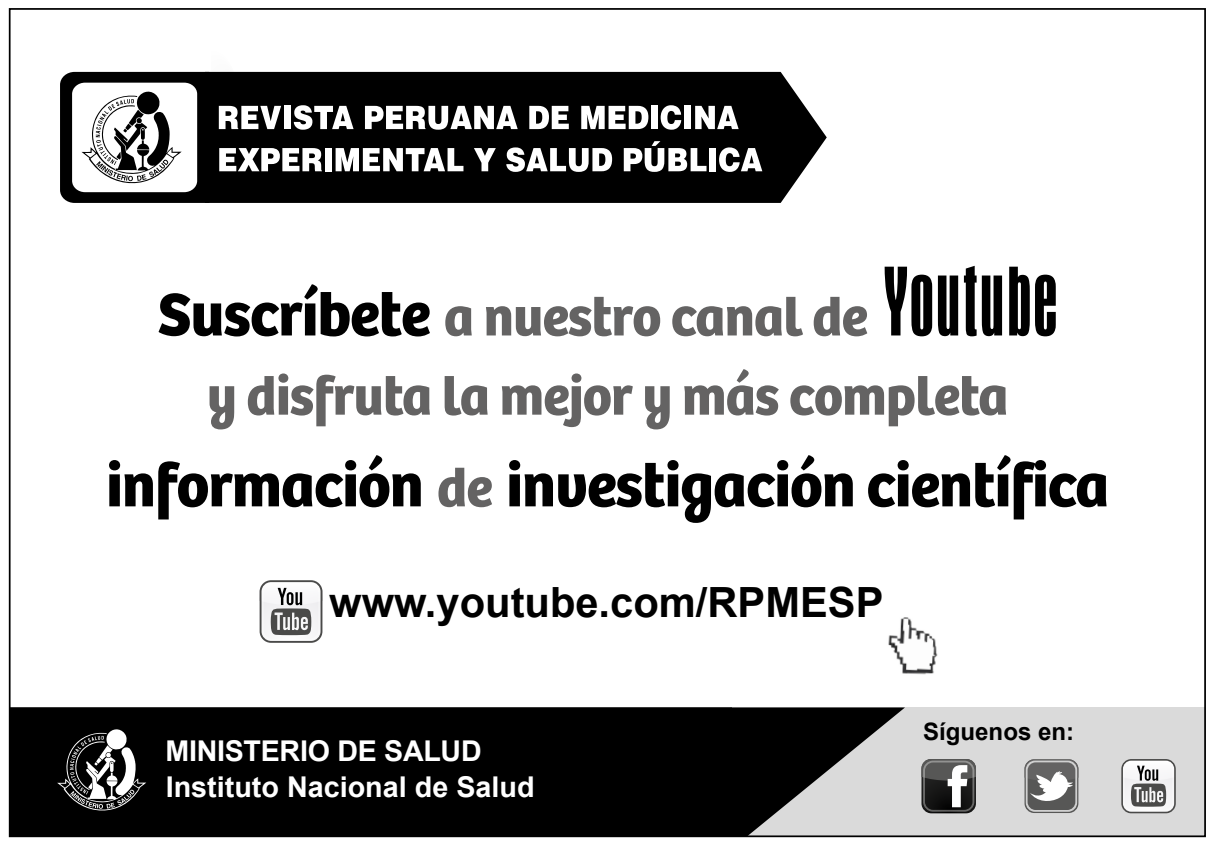

